Article

\title{
Energy and Environmental Flows: Do Most Financialised Countries within the Mediterranean Area Export Unsustainability?
}

\author{
Pietro Vozzella ${ }^{1, *(1)}$, Franco Ruzzenenti ${ }^{2}$ (D) and Giampaolo Gabbi ${ }^{1}$ (i) \\ 1 Department of Business and Law, University of Siena, Via S. Francesco 1, IT-53100 Siena, Italy \\ 2 Energy and Sustainability Research Institute, University of Groningen, Nijenborgh 6, 9747 AG Groningen, \\ The Netherlands \\ * Correspondence: pietro.vozzella@unisi.it
}

Received: 26 May 2019; Accepted: 28 June 2019; Published: 9 July 2019

check for updates

\begin{abstract}
The literature dedicated to the problems of transboundary pollution often aims to verify what the environmental and energy interactions between countries are. Little attention is paid to the financial relations of the phenomenon. We analyze how financial, environmental and energy flows have been redistributed within the main Mediterranean countries, with particular reference to pollution. Applying advanced methods of correlation, we verify the dynamics of transfer processes with the aim of assessing whether the link between economic and financial and environmental flows might support the hypothesis that rich countries export environmental emissions to poor ones. Our results show that richer countries have a significant propensity to export energy, financial flows and polluting emissions. The imbalance is even greater for emissions with local impact. This process is accompanied by a substantial increase in the financial activities of the North Mediterranean countries to the detriment of those of the South, which progressively increase their indebtedness. We find out that the economic and financial development of the North Med is accompanied by an increasing environmental impact measured by the various types of emissions covered by our study. The research shows how the most industrialized countries of the Mediterranean area are increasing the economic and financial gap with respect to the Southern Mediterranean countries.
\end{abstract}

Keywords: trade; finance; virtual environmental network; embodied energy flows; network theory; multiplex; reciprocity

\section{Introduction}

The trend in inequalities shows that disparities in per capita income between Mediterranean economies increased until 1970, stabilised until the mid-1980s, and then increased again [1]. The factors that characterize the economic differences between countries have been analyzed from different perspectives: social, legal and political [2]. Less attention has been paid to the energy implications of inequalities and to the interconnection between financial and environmental flows, which can affect the pollution of the Mediterranean countries in various ways. As stated within the report from the UN Intergovernmental Panel on Climate Change 2014 Report, a growing share of $\mathrm{CO}_{2}$ emissions from fossil fuel combustion in developing countries is released in the production of goods and services exported, notably from upper-middle-income countries to high-income countries [3]. The literature devoted to transboundary pollution problems uses a game theoretical framework to express important strategic interactions between countries in addressing the problem of climate change [4-8]. Along the same lines, the broad literature focused on environmental and climate justice has advocated for a reduction in inequality as a tool to address environmental problems $[9,10]$. Boyce [11], in analysing the 
phenomenon of the unequal exchange of environmental resources between rich and poor countries, wonders who the winners are and, above all, why they can impose the relative costs on the losers. The last question has three possible answers. One is that losers do not yet exist. They belong to future generations, and therefore are not here to defend themselves. The second possibility is that losers already exist, but they do not know it. They lack information on the costs of environmental degradation. The third possibility is that losers exist and know it, but they do not have the power to prevent winners from imposing costs on them.

Our research has as its first objective that of verifying whether the possible balance of power between rich and emerging countries in the Mediterranean area exists and how it can be quantified. We analyze how financial and virtual environmental flows (environmental emissions embodied in goods) have been redistributed within the ten main Mediterranean countries, with particular reference to pollution. Six types of virtual environmental flows and three kinds of financial flows can generate a very large number of interactions' patterns and a complex, enveloping structure. The nexus between resources' or virtual flows (layers) in this complex system can be studied with several methodologies [12,13] - in a few cases, these flows have been associated with financial flows [14,15]. Applying advanced methods of correlation and network analysis [16], we verify the dynamics of transfer processes with the aim of assessing whether the link between economic and financial inequality and the hypothesis that rich countries export environmental emissions to poor ones are confirmed. Our research questions may be stated as follows: are financial flows correlated and linked with virtual energy flows? Are Southern Mediterranean countries importing pollution from Northern ones? The allocation of emissions embodied in international trade and in financial flows is crucial to evaluate the real impact that each country has on environmental pollution and its sustainability. Therefore, the attribution of emissions becomes a crucial issue when we want to reveal the redistribution of pollution.

The analysis on environmental bilateral flows presented here is based on data drawn from multiregional input-output (MRIO) Eora database, which is a consumption-based accounting method. This method, in contrast to the production-based approach which estimates emissions released within a specific geographical area, attributes emissions to the final consumers of goods and services. The rest of the paper is organized as follows. In Section 2, we describe data and methodology, which encompasses features of international pollution stock, emission technology, and financial flows countries. In Section 3, we present our results and in Section 4 we discuss our results. Finally, we offer concluding comments and suggestions.

\section{Data and Materials and Methods}

\subsection{Data}

Our analysis focuses on the Mediterranean area and covers the top 10 countries on all sides for which there is a coherent set of bilateral environmental and financial trade information: Cyprus, Egypt, France, Greece, Italy, Israel, Lebanon, Malta, Spain and Turkey. In the analysis of the network, all of these countries represent the nodes, while the borders are represented by cross-border environmental and financial flows. In particular, our observations contain six environmental dimensions (emissions of $\mathrm{NO}_{x}, \mathrm{PM} 10, \mathrm{SO}_{2}, \mathrm{CO}_{2}$ equivalent emissions and water footprint in gigagrams (Gg), Energy in tera joules (TJ)) and three financial dimensions (Equity, Long-Term Debt and Short-Term Debt). The observation period is from 2002 to 2015. Data on environmental impacts come from Eora's multi-regional input-output table (MRIO) which provides a time series of high-resolution I/O tables with corresponding environmental and social satellite accounts for 190 countries. The Eora MRIO database reports the direct and indirect flows of resource footprints between producers and final consumers aggregated at a national level. The data describe in detail the countries of origin of each footprint, reporting the embedded flows from each country of origin/issuer to each country of 
destination/consumption. Referring to the environmental footprint associated with consumption in a given country, the embedded flows are to be understood as virtual for the resource footprint.

Most empirical studies on the determinants of international capital flows usually focus only on foreign direct investment (FDI) because the analyses find out more on capital flows than on stocks of foreign investment. In contrast, in our study, data on financial transactions are taken from the Coordinated Portfolio Investment Survey (CPIS) conducted by the IMF. The CPIS records portfolio investment data in the form of shares and units in investment funds, long-term debt securities and short-term debt securities vis-à-vis more than seventy counterparty economies. All financial data are in millions of US dollars. They refer to the end of the year of the periods and do not provide information on portfolio flows. This choice allows us to keep all financial variables consistent and avoid having a matrix of financial margins calculated differently, with a negligible impact on the correlation analysis and, therefore, on the analysis of the output network. This approach is supported by many recent studies [17] suggesting that foreign direct investment and portfolio investment can be treated as substitutes.

Based on the above explanations, we calculated, as a proxy for financial flows from country $i$ to country $j$, the difference between two consecutive total amounts on assets held by residents of country $i$ ( $i$ to $j$ ) [18]. Although previous studies $[19,20]$ have already highlighted the drawbacks of CPIS data in terms of incompleteness, a lack of strong data consistency and the risk of undervaluation arising from the voluntary nature of the survey, due to the simultaneity of the survey and the use of consistent definitions, data collection is homogeneous and the geographical breakdown is very large for a comprehensive analysis of capital flows.

\subsection{Pearson Correlation Index for Multiplex Networks}

A first method to investigate layers' correlations in a multiplex framework was proposed by Garlaschelli and applied to the commodity-specific trades [21]. Garlaschelli extended the Pearson correlation index to the multiplex by averaging over space instead of time. The Pearson correlation index between the layers A and B (at time $t$ ) will thus be:

$$
\rho_{>>}^{A B} \equiv \frac{\sum_{i \neq j}\left(w_{i j}^{A}-\mu^{A}\right)\left(w_{i j}^{B}-\mu^{B}\right)}{\sqrt[2]{\sum_{i \neq j}\left(w_{i j}^{A}-\mu^{A}\right)^{2}\left(w_{i j}^{B}-\mu^{B}\right)^{2}}}=\frac{\operatorname{cov}_{A B}}{\sigma_{A} \sigma_{B}} .
$$

It is noteworthy that the above definition of correlation can be applied both to links going in the same direction (Equation (1)) and to links going in opposite directions (Equation (2)):

$$
\rho_{><}^{A B} \equiv \frac{\sum_{i \neq j}\left(w_{i j}^{A}-\mu^{A}\right)\left(w_{j i}^{B}-\mu^{B}\right)}{\sqrt[2]{\sum_{i \neq j}\left(w_{i j}^{A}-\mu^{A}\right)^{2}\left(w_{j i}^{B}-\mu^{B}\right)^{2}}} .
$$

\subsection{Second Correlation Measure: Multiplexity and Multireciprocity}

Recently, a more refined measure of correlation across layers in a (weighted) multiplex has been proposed [16]. This measure derives from the extension of concept of reciprocity in weighted networks (see [22]) to the context of multiple layers networks, and reads as follows:

$$
m^{A B}=\frac{2 \sum_{i \neq j} \min \left[w_{i j}^{A}, w_{i j}^{B}\right]}{\sum_{i \neq j} w_{i j}^{A}+\sum_{i \neq j} w_{i j}^{B}}
$$

for flows in the same direction, and:

$$
r^{A B}=\frac{2 \sum_{i \neq j} \min \left[w_{i j}^{A}, w_{j i}^{B}\right]}{\sum_{i \neq j} w_{i j}^{A}+\sum_{i \neq j} w_{i j}^{B}}
$$


for flows in the opposite direction. Multiplexity (Equation (3)) and multireciprocity (Equation (4)) are both normalized measures, spanning from 0 to 1 . In the former case layers, $A$ and $B$ never overlap across the entire network; in the latter, they perfectly overlap, meaning that they are perfectly correlated. A multiplex features homogeneous layers-the same units, or heterogeneous-different units. When a multiplex is heterogeneous, all flows are normalized to the relative total flow $W$ and become unit-less (scalar).

Any measure of correlation across layers (inter-layers) is sensitively dependent on the internal topology of each layer (intra-layer). Put simply, if two layers share the same hubs, any correlation results trivially from the mere overlap the two internal structures. Figure 1 shows, by the means of a very simple and stylized multiplex with three nodes and two layers, to what extent the reciprocity structure within each layer can affect the observed correlation between layers (width of the arrows indicates the intensity of the flows). Prima facie, the red and yellow layers seem to be very correlated when moving across nodes. Nevertheless, this is due the combined effect of the reciprocity level within each layer and the topology of the multiplex. For instance, node $C$ is a hub in both layers and thus node $A$ and $B$ tend to exchange with $C$ more than between each other.

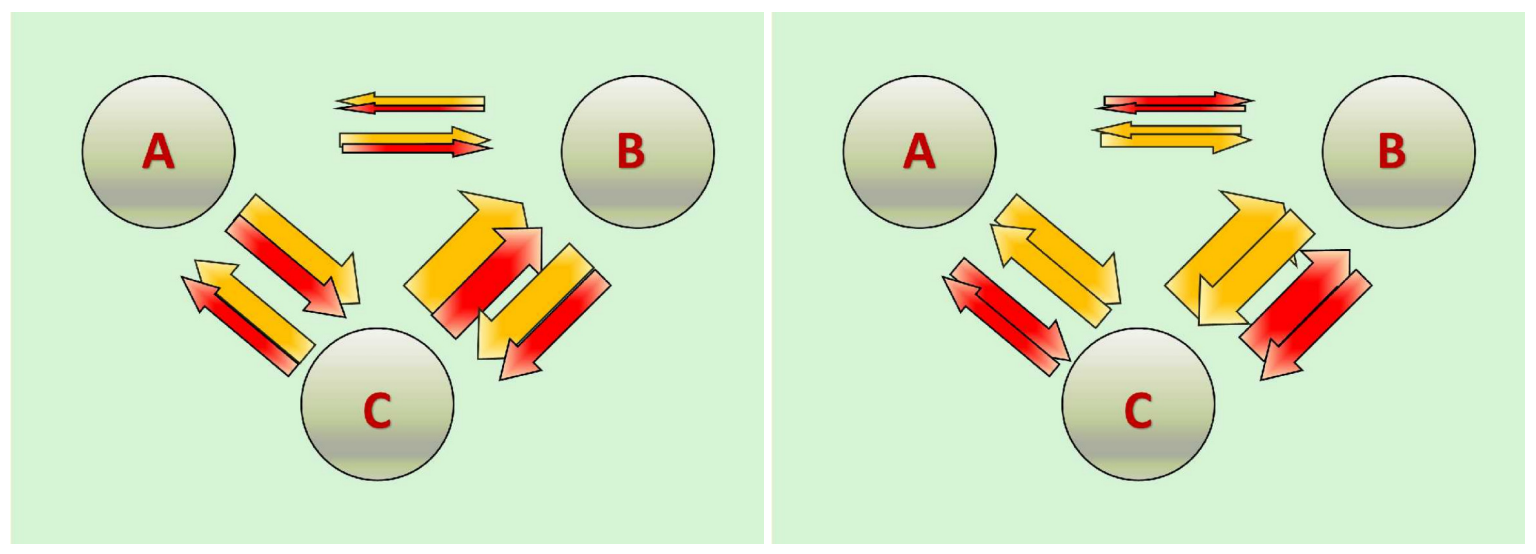

Figure 1. Disentangling correlation and reciprocity across layers.

Measures (3) and (4), differently from measure (2) and (1), permit the inclusion of suitable null models in the analysis and the development of an enhanced measure of correlation, cleaned by the intra-layer topological effects.

In [16], the following enhanced measure of multiplexity between two generic layers $A$ and $B$ is proposed and denoted as $\mu$ :

$$
\mu^{A B}=\frac{m^{A B}-\left\langle m^{A B}\right\rangle}{1-\left\langle m^{A B}\right\rangle}
$$

and enhanced multireciprocity $\rho$ :

$$
\rho^{A B}=\frac{r^{A B}-\left\langle r^{A B}\right\rangle}{1-\left\langle r^{A B}\right\rangle}
$$

where

$$
\left\langle m^{A B}\right\rangle=\frac{\sum_{i \neq j}\left\langle w_{i j}^{A}\right\rangle\left\langle w_{i j}^{B}\right\rangle}{\sum_{i \neq j}\left\langle w_{i j}^{A}\right\rangle \sum_{i \neq j}\left\langle w_{i j}^{B}\right\rangle}
$$

and

$$
\left\langle r^{A B}\right\rangle=\frac{\sum_{i \neq j}\left\langle w_{i j}^{A}\right\rangle\left\langle w_{j i}^{B}\right\rangle}{\sum_{i \neq j}\left\langle w_{i j}^{A}\right\rangle \sum_{i \neq j}\left\langle w_{j i}^{B}\right\rangle} .
$$

Both $\mu$ and $\rho$ can be positive or negative, indicating a positive or negative correlation in excess to the random correlation as captured by the null model and score 0 when the two layers are uncorrelated. It is noteworthy that $\mu$ and $\rho$ can vary freely without any upper or lower bound. 


\subsection{Models}

A null model is meant to test the statistics significance of results, on the one hand, and to enhance the correlation analysis by clearing them from undesired side effects generated by the complexity of the interactions' structure, on the other. In order to clear correlation measures across layers of the topological effects, we adopt the formalism of Exponential Random Graphs or $p^{*}$ models, which allow for obtaining maximally random ensembles of networks with specified constraints.

The method is composed by two main steps: the first one is the maximization of the Shannon entropy over a previously chosen set of graphs, $\mathcal{G}$

$$
S=-\sum_{G \in \mathcal{G}} P(G) \ln P(G)
$$

under a number of imposed constraints [23], generically indicated as

$$
\sum_{G \in \mathcal{G}} P(G)=1, \quad \sum_{G \in \mathcal{G}} P(G) \pi_{a}(G)=\left\langle\pi_{a}\right\rangle, \forall a
$$

(note the generality of the formalism, above: $G$ can be a directed, undirected, binary or weighted network). We can immediately choose the set $\mathcal{G}$ as the grandcanonical ensemble of binary directed graphs, i.e., the collection of networks with the same number of nodes of the observed one (say $N$ ) and a number of links, $L$, varying from zero to the maximum (i.e., $N(N-1)$ ). This prescription leads to the exponential distribution over the previously chosen ensemble

$$
P(G \mid \vec{\theta})=\frac{e^{-H(G, \vec{\theta})}}{Z(\vec{\theta})},
$$

whose coefficients are functions of the Hamiltonian, $H(G, \vec{\theta})=\sum_{a} \theta_{a} \pi_{a}(G)$, which is the linear combination of the chosen constraints. The normalization constant, $Z(\vec{\theta}) \equiv \sum_{G \in \mathcal{G}} e^{-H(G, \vec{\theta})}$, is the partition function [23]. The second step prescribes how to numerically evaluate the unknown Lagrange multipliers $\theta_{a}$. Let us consider the log-likelihood function $\ln \mathcal{L}(\vec{\theta})=\ln P(G \mid \vec{\theta})$ and maximize it with respect to the unknown parameters. In other words, we have to find the value $\vec{\theta}^{*}$ of the multipliers satisfying the system

$$
\left.\frac{\partial \ln \mathcal{L}(\vec{\theta})}{\partial \theta_{a}}\right|_{\vec{\theta}^{*}} \equiv 0, \forall a
$$

or that is the same,

$$
\pi_{a}(G)=\left\langle\pi_{a}\right\rangle\left(\vec{\theta}^{*}\right) \equiv\left\langle\pi_{a}\right\rangle^{*}, \forall a
$$

i.e., a list of equations imposing the value of the expected parameters to be equal to the observed one. Note that the term "expected", here, refers to the weighted average taken on the grandcanonical ensemble, the weights being the probability coefficients defined above. Thus, once the unknown parameters have been found, it is possible to evaluate the expected value of any other topological quantity of interest, $X$ :

$$
\langle X\rangle^{*}=\sum_{G \in \mathcal{G}} X(G) P\left(G \mid \vec{\theta}^{*}\right) .
$$

Because of the difficulty to analytically calculate the expected value of the quantities commonly used in complex networks theory, it is often necessary to rest upon the linear approximation method: $\langle X\rangle^{*} \simeq X\left(\langle G\rangle^{*}\right)$, where $\langle G\rangle^{*}$ indicates the expected adjacency matrix, whose elements are $\left\langle a_{i j}\right\rangle^{*} \equiv p_{i j}^{*}$. For the weighted directed version of networks, a very useful null model is the weighted directed 
configuration model (WDCM) that imposes the in and out strength sequence for every node (that is, the import and export sequence for every layer). The Hamiltonian will thus be:

$$
H_{W D C M}=\sum_{i}\left(\alpha_{i} s_{i}^{i n}+\beta_{i} s_{i}^{\text {out }}\right)=\sum_{i \neq j}\left(\alpha_{j}+\beta_{i}\right) w_{i j} .
$$

\section{5. $z$-Score and Statistical Validation}

The transformed quantities defined in (5) and (6) capture the similarity (correlation) between layers in a multiplex by comparing the empirical values with the expected values under a null model (the WDCM, Equation (15)). However, those quantities do not consider any information about the variances of the values of multiplexity and multireciprocity under the null model, thus giving no direct information about statistical significance. Given the absence of any parametric scale, it is difficult to disentangle, weak interlayer dependencies from pure noise. Put simply, if 0 signals that two layers are uncorrelated, what is the band of decimal values that are acceptable (i.e., significant) under the constraints we imposed? Moreover, the random fluctuations around the expectation values will in general differ for different pairs of layers, making our choice even more difficult and arbitrary. A way to solve this problem is to accept only those values that exceed a given number (threshold) of standard deviations of the mean value, more formally, for the multiplexity:

$$
z\left(m^{A B}\right) \equiv \frac{m^{A B}-\left\langle m^{A B}\right\rangle}{\sqrt{\left\langle\left(m^{A B}\right)^{2}\right\rangle-\left\langle m^{A B}\right\rangle^{2}}}
$$

and for the multireciprocity:

$$
z\left(r^{A B}\right) \equiv \frac{r^{A B}-\left\langle r^{A B}\right\rangle}{\sqrt{\left\langle\left(r^{A B}\right)^{2}\right\rangle-\left\langle r^{A B}\right\rangle^{2}}} .
$$

For the explicit analytical expressions for these $z$, see [16]. The z-scores have the same signs as the corresponding quantities (see [16] for demonstration), but in addition they allow us to test for statistical significance using, e.g., a threshold of $z_{c}=2$ as in our case.

\section{Results}

\subsection{Descriptive Statistics}

The research is based on two categories of information: financial and environmental. As the two types of flows have different units of measurement both within and between them, data have been standardised to eliminate differences in units of measurement and make them comparable across countries. The standardisation is done for each country by dividing the difference between total export and import flows by the sum of total export and import flows. Data considered are exclusively those that are exchanged between the Mediterranean countries under analysis. Therefore, all environmental and financial flows transferred between residents within each country are not considered. We have obtained a range $(-1 ;+1)$ for all environmental and financial variables for each country. Negative (positive) imbalance values identify countries that are net importers (exporters) of environmental and financial flows, respectively. Table 1 (layers from 4 to 9) shows that, throughout the sample period, the environmental imbalances between the Mediterranean countries that we consider in our analysis present a rather heterogeneous picture. 
Table 1. Environmental and financial imbalance across Mediterranean Countries (Average 2002-2015). Source: Author's elaboration on the Eora MRIO database and Coordinated Portfolio Investment Survey (CPIS) database.

\begin{tabular}{llllllllllll}
\hline & Layer & Cyprus & Egypt & France & Greece & Israel & Italy & Lebanon & Malta & Spain & Turkey \\
\hline 1 & Equity & -0.12 & -0.40 & 0.14 & -0.21 & 0.37 & 0.21 & 0.45 & -0.70 & 0.00 & -0.66 \\
2 & Long T.D. & 0.33 & 0.15 & 0.34 & -0.29 & -0.06 & -0.26 & -0.12 & 0.82 & -0.31 & -0.91 \\
3 & Short T.D. & -0.27 & 0.54 & 0.38 & -0.12 & -0.08 & -0.39 & -0.05 & -0.14 & -0.31 & -0.53 \\
\hline 4 & Air $\mathrm{NO}_{x}$ & 0.39 & -0.17 & 0.55 & 0.72 & 0.85 & -0.42 & -0.68 & 0.75 & -0.86 & 0.75 \\
5 & ${\text { GHG } \mathrm{CO}_{2}}_{2}-0.20$ & -0.77 & 0.62 & 0.85 & 0.35 & -1.00 & 1.00 & 0.86 & 0.99 & -0.99 \\
6 & Air $\mathrm{PM}_{10}$ & -0.89 & -0.95 & 0.98 & 0.99 & 0.93 & 1.00 & 0.05 & -1.00 & -1.00 & 0.20 \\
7 & Air $\mathrm{SO}_{2}$ & -0.34 & -0.72 & 0.87 & 0.94 & -0.99 & -0.83 & -0.98 & -0.99 & -0.22 & -0.22 \\
8 & Water & 0.31 & -0.81 & 0.11 & 0.67 & 1.00 & -0.11 & -0.85 & 0.94 & -1.00 & 0.99 \\
9 & Energy & -0.91 & 0.76 & 1.00 & 0.18 & -0.85 & -0.96 & -1.00 & -0.17 & 0.85 & -0.59 \\
\hline
\end{tabular}

However, we can find some countries showing the same performance for all environmental dimensions. In particular, France and Greece are net exporters of environmental flows, while Egypt and Italy, with the exception of energy and Air PM10, respectively, are net importers of emissions. Focusing on $\mathrm{CO}_{2}$ emissions, we find out that Italy shows the most relevant imbalance. Our finding is coherent with previous studies focused on the Mediterranean that have found this area resulted as a net importer of $\mathrm{CO}_{2}$ emissions embodied in traded goods and that, among Mediterranean countries, the most relevant flows of $\mathrm{CO}_{2}$ emissions come from Italy to France [24]. This evidence confirms the hypothesis underlying the production-based accounting approach according to which an imports-oriented country will allocate a lower amount of emissions than the ones induced the domestic consumption $[25,26]$. On the contrary, a country whose economy is mainly exports-oriented will have, for a given amount of final consumption, more direct emissions than a non-exporting country [27,28]. Table 1 shows the imbalance in financial flows between the countries analysed. The heterogeneity between countries is lower and most of them show the same net positions for most layers. As already seen for environmental flows, France is also a net exporter to other countries for all financial activities, while Greece remains a net importer also for financial trade. Equity is the layer with the highest variability while most of the countries are net importers of debt financial flows, especially short-term debt. The exceptions refer to Cyprus, Malta, Egypt and France for long-term debt and the two latter for short-term debt. Interestingly and consistent with what we expected, Italy is a net exporter of equity and, as we have seen above for environmental margins, is a net importer both of long- and short-term financial flows. This result is consistent with the foreign exposure of the Italian public debt, in particular for the entire period of our sample. In Figure 2, we show a picture of the environmental and financial imbalances analysed jointly within each country.

The diagrams measure the aggregation of normalised environmental and financial imbalances for each country. In this case, as a proxy of financial flows we have considered total portfolio investment. With regard to environmental flows, we aggregate $\mathrm{NO}_{x}, \mathrm{SO}_{2}, \mathrm{PM} \mathrm{N}, \mathrm{CO}_{2}$ and Water due to being characterized by the same unit of measurement $(\mathrm{Gg})$ and we separately consider Energy because it is computed in tera joules (TJ). Overall, as far as environmental air emissions are concerned, among the Mediterranean countries we have considered, France, Greece and Malta as net exporters, while Cyprus, Egypt, Lebanon, Italy, Spain and Turkey as net importers. Israel is substantially in the balance, exports and imports of environmental flows tend to balance each other. Differently, when Energy is considered, Cyprus, Israel, Italy, Lebanon, Malta and Turkey result as net importers while Egypt, France, Spain and, to a lesser extent, Greece are net exporters. As far as financial flows are concerned, France, Malta, and partially Cyprus are the only countries with a significant positive imbalance (net exporter), while Egypt, Italy, Spain and, more severely, Greece and Turkey show a negative imbalance. Lebanon shows a substantially balance between outgoing and incoming financial flows. Finally, Table 2 shows the ranking of the Revealed Comparative Advantages (RCA) of our sample of the Mediterranean countries in relation to the six environmental dimensions considered in our study. The aim of the RCA is to indicate whether a country's share of the world product market is greater or less than the 
product share of the entire world market. It is used in international economics to calculate the relative advantage or disadvantage of a certain country in a certain class of goods or services. RCA most commonly refers to an index introduced by Béla Balassa [29]: a comparative advantage is revealed if $R C A>1$, whereas, if $R C A$ is less than unity, the country is said to have a comparative disadvantage in the commodity or industry. In our study, the total market is represented by our sample of the Mediterranean area. Countries that have a comparative advantage to pollute within their borders and, therefore, to export goods are at the top of the pyramid; conversely, a country below has a comparative advantage to produce outside the borders and to import the final consumption. In line with the picture outlined above, this indicator also shows a high heterogeneity between environmental emissions and does not draw a clear line of demarcation between net exporters and importers. It suggests that the matrix of Mediterranean countries in our study is characterized by intricate patterns of trade and trade relations that could reflect both the economic strategies and characteristics of the production systems of each country and the need to maintain an economic and political balance in the region between countries.

\section{Total Emissions vs Total Portfolio Imbalances}

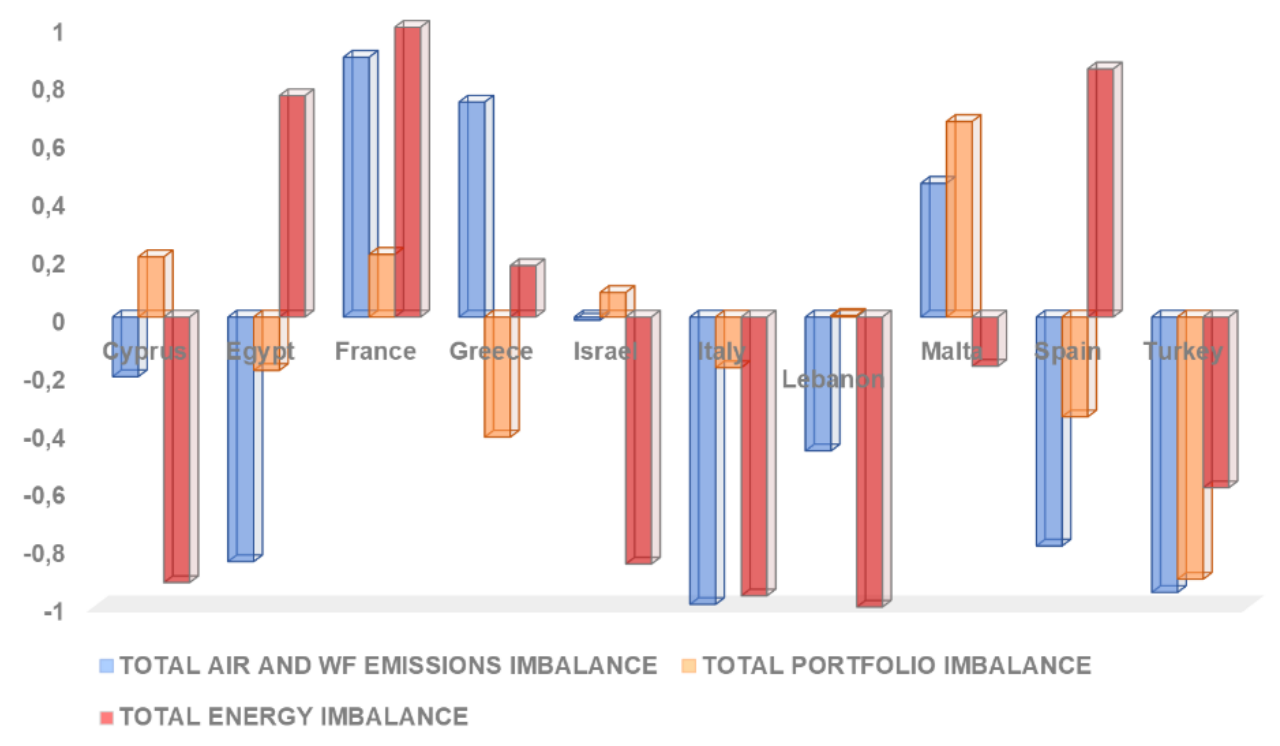

Figure 2. Total emissions and total portfolio imbalances (average 2002-2015). Source: Authors' elaboration on Eora MRIO and Coordinated Portfolio Investment Survey (CPIS) database.

Table 2. Revealed Comparative Adventage (RCA) between Mediterranean Area (Average 2002-2015). Source: Author's elaboration on the Eora MRIO database.

\begin{tabular}{ccccccc}
\hline Ranking & Air $\mathrm{NO}_{x}$ & Air $\mathrm{SO}_{2}$ & Air PM10 & Energy & GHG $\mathrm{CO}_{2}$ & WaterFootprint \\
\hline 1 & Cyprus & Israel & Greece & France & Israel & Cyprus \\
2 & Malta & Egypt & Turkey & Cyprus & France & Malta \\
3 & Lebanon & Italy & Spain & Egypt & Egypt & Turkey \\
4 & Turkey & Turkey & France & Turkey & Italy & Spain \\
5 & Spain & Greece & Egypt & Israel & Greece & Lebanon \\
6 & Egypt & Malta & Cyprus & Italy & Turkey & Egypt \\
7 & Italy & Lebanon & Israel & Greece & Lebanon & France \\
8 & Israel & Cyprus & Italy & Malta & Cyprus & Israel \\
9 & Greece & France & Lebanon & Lebanon & Malta & Greece \\
10 & France & Spain & Malta & Spain & Spain & Italy \\
\hline
\end{tabular}


The following analysis is aimed at finding out whether the spatial scale of the different sources of pollution affects their distribution. Since environment and climate change is a phenomenon combining global with local characteristics, starting from [30], we grouped the environmental flows in three categories: local, glocal and global emissions. Local emissions are those that impact essentially in the vicinity of the place that originated them, unlike global emissions, which have a wide (global) distribution effect. A third category is that of glocal emissions, characterised by a dual impact, both local and global. Local are considered emissions of $P M 10, \mathrm{SO}_{2}$ and water footprint. Emissions of $\mathrm{NO}_{x}$ are considered to be glocal and, finally, $\mathrm{CO}_{2}$ is considered to have a global dimension. Energy is not considered. Interestingly, as we have seen above, we can observe that France and Greece are net exporters of all types of environmental flows, whereas all other countries are net importers of local impact emissions while they show a certain heterogeneity regarding to glocal and global. Italy and Egypt are always net importers of emissions; Israel and Malta are net importers of local impact emissions and net exporters of those glocal and global. In contrast, Lebanon and Spain are net importers of local and glocal emissions and net exporters of those global. Finally, Cyprus and Turkey are net importers of local and global impact emissions and net exporters of those glocal (Table 3).

Table 3. Imbalance of Local, Glocal and Global impact emissions across countries (average 2002-2015). Source: Author's elaboration on the Eora MRIO database.

\begin{tabular}{cccc}
\hline Countries & Local Impact Emission & Glocal Impact Emission & Global Impact Emission \\
\hline Cyprus & -0.520 & 0.388 & -0.202 \\
Egypt & -0.870 & -0.166 & -0.770 \\
France & 0.949 & 0.546 & 0.623 \\
Greece & 0.805 & 0.725 & 0.855 \\
Israel & -0.836 & 0.855 & 0.348 \\
Italy & -0.514 & -0.423 & -1.000 \\
Lebanon & -0.854 & -0.681 & 1.000 \\
Malta & -0.985 & 0.747 & 0.855 \\
Spain & -0.989 & -0.856 & 0.995 \\
Turkey & -0.211 & 0.749 & -0.991 \\
\hline
\end{tabular}

\subsection{Network Analysis}

Figure 3 shows the temperature map or multiplexity and multireciprocity (Equations (3) and (4)) averaged over the years 2002-2015. Multiplexity and multireciprocity are normalized (varying between 0 and 1 ) indicators of the overlapping degree of layers in a multiplex (a network with multiple kind of flows), for flows in the same and in the opposite direction. Equity has a slightly higher degree of overlapping with environmental layers compared to the other financial flows. However, long-term debt shows a remarkable strong, reverse nexus with $\mathrm{SO}_{2}$ and energy. Reverse flows also show a higher overlapping and, surprisingly, the nexus between environmental and financial layers is more intense than that among environmental layers, with the exception of the nexus between water and $N O_{x}$. Remarkable also is how equity and long term debt form a very strong, reverse nexus (flows in the opposite direction).

Figure 4 shows the temperature maps of the correlation matrix of the significant values (z-score greater than 2) of the enhanced multiplexity $\mu$ and multireciprocity $\rho$ respectively, averaged over the years 2002-2015. Here, values can be positive or negative, reflecting the extent to which the overlapping of flows is more or less explained by the overlapping of topologies. We will use the term correlation in a broad sense and, although the measure is not normalized, it generally varies between -1 and +1 , regardless of the pair matching of flows' direction. When the value is positive (negative), it means that more flow of one type corresponds to more (less) flow of another type, regardless of the similarity between the two layers' topology (i.e., they share the same hubs). To put it simply, here synergism does not depend on trade relationships-some other intrinsic mechanism is at work. When the value 
is 0 , the observed overlapping is fully explained by topology (trade relationships). For flows in the same (multiplex) and in the opposite (reciprocal) direction, equity and long-term debt show in most cases a negative correlation with the environment. Only $\mathrm{SO}_{2}$, which is mainly due to coal combustion, either from the power sector or metallurgy, show a positive correlation with financial flows, mostly for opposite flows. Short-term debt in most cases shows no significant correlations, with the exception of a positive, multiplex correlation with energy.
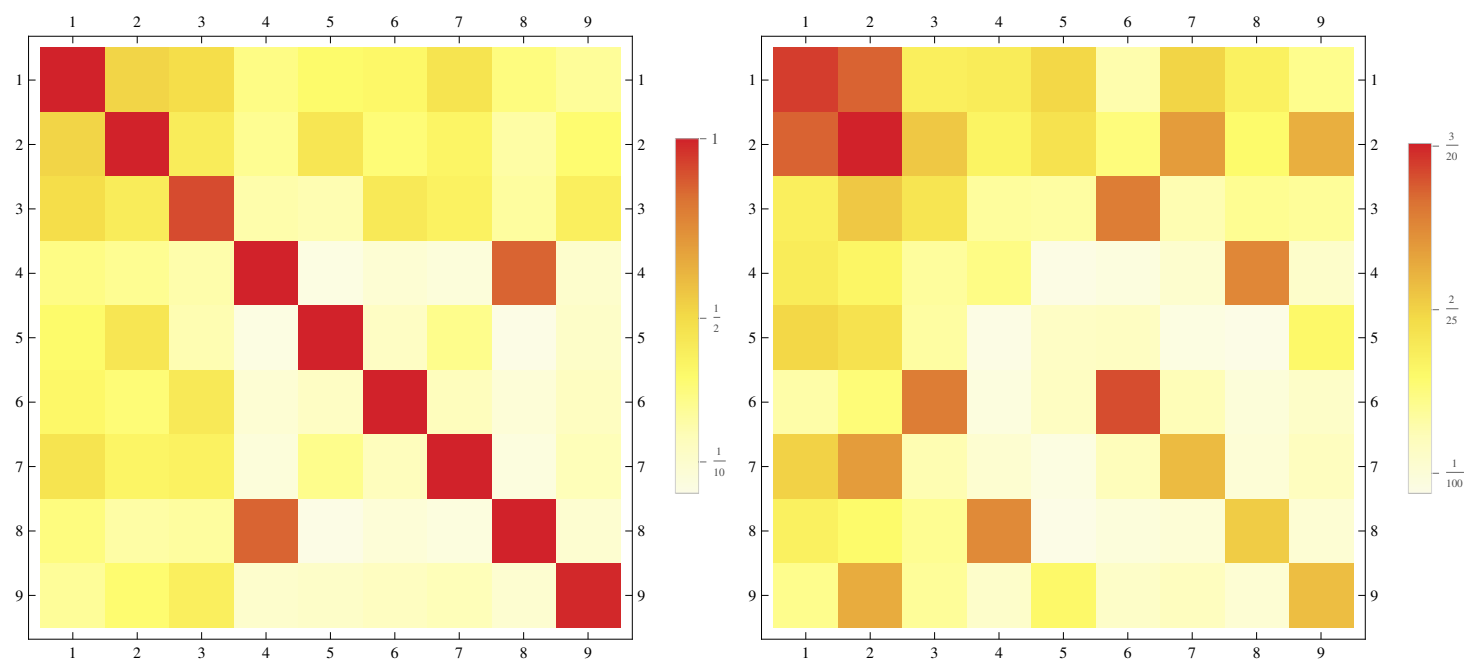

Figure 3. Temperature maps of multiplexity and multireciprocity, Equations (3) and (4), averaged over the years 2002-2015. The intensity of the colour, from white (score $=0$ ) to red (score $=1)$, indicates the overlapping degree between couple of layers across the whole network, for flows in the same and opposite directions.
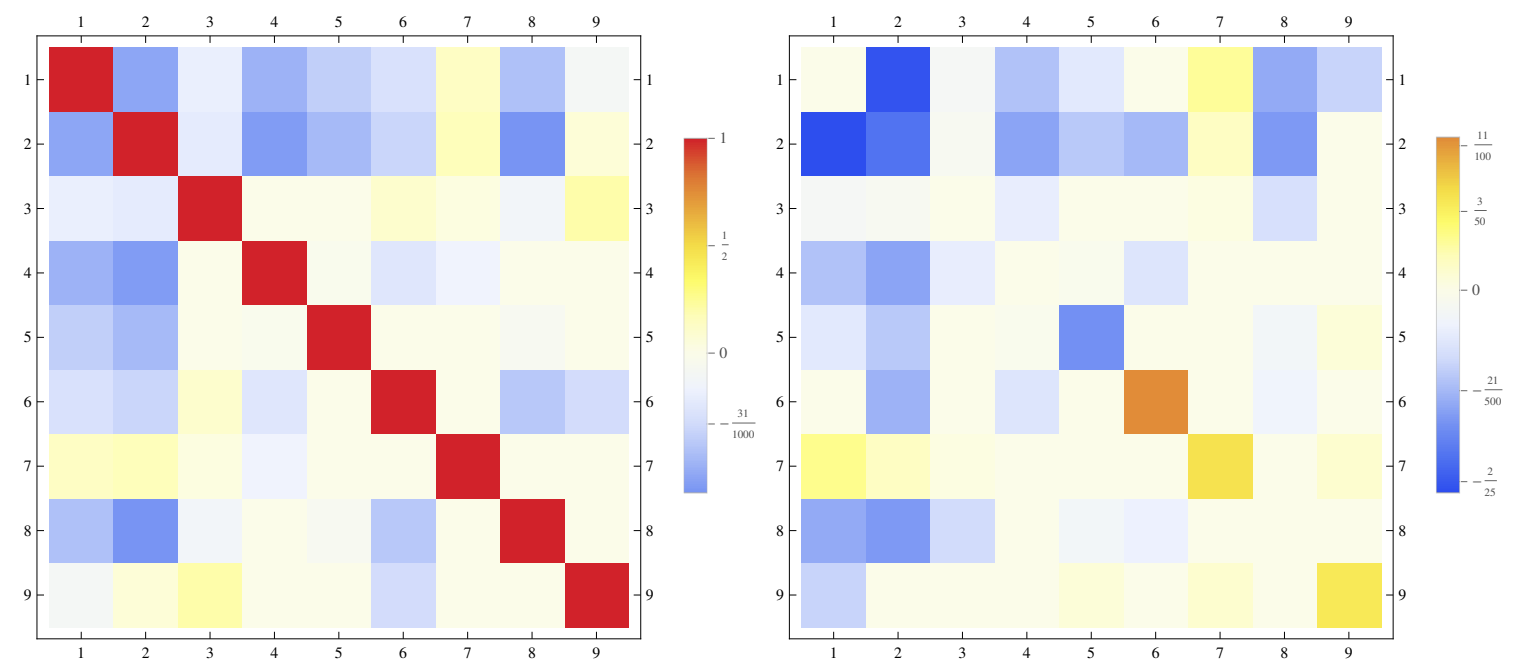

Figure 4. Temperature maps of the enhanced multiplexity and multireciprocity, Equations (5) and (6), with z-score $>2$, averaged over the years 2002-2015. White indicates no significant correlation, shades of yellow positive and shades of blue negative correlations, for flows in the same and in opposite direction.

\section{Discussion}

Many studies focused on the worldwide increasing connection and environmental exchange [31,32]. The transfer of embodied emissions flows in commodity production affects the environmental system in trading area [32,33]. Xu et al. [15] (2018) found that, over time, all flows between distant countries are increased more than those between adjacent countries. Furthermore, large increases in virtual resource flows also affect the financial capital flows between 
countries [34]. Some empirical evidence has recently found that more financialised countries display higher correlations between outgoing financial flows and incoming environmental flows than from lower financialised countries [14]. In Figure 5, we show the imbalance of environmental emissions between the top 10 countries of the North and South Mediterranean areas. All of the EU countries of our sample (Cyprus, France, Greece, Italy, Malta and Spain) are classified as the North area, whereas Egypt, Israel, Lebanon and Turkey are within the South area. Interestingly, and consistent with the results in Ruzzenenti et al. [14], data show an opposite pattern between North and South Mediterranean countries, suggesting that the former, generally more financial developed, are net exporters of energy and emissions, whereas the latter are net importers.

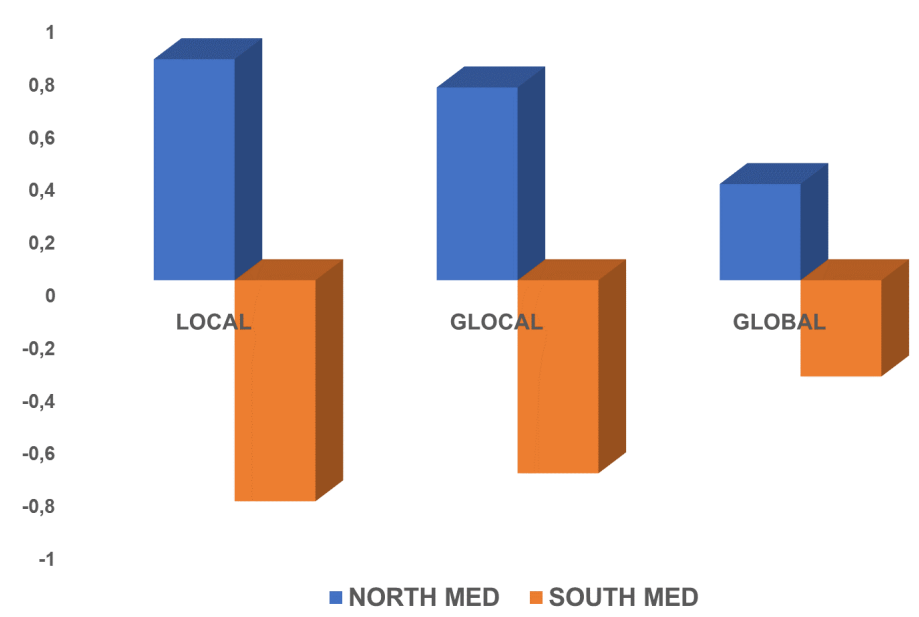

Figure 5. Imbalance of Environmental Emissions between the North and South Mediterranean Areas (average 2002-2015). Source: Authors' elaboration on the Eora MRIO database

With regard to energy transfer, we have observed that the Mediterranean countries that are part of the EU export to other countries in our sample an average of 551,120 terajoules. The process of exporting energy from the north to the south, associated with that of financial flows, can be oriented towards boosting production in the less industrialised countries of the area. This hypothesis may be confirmed by the analysis of the flows of environmental emissions. We observe that the gap of exchange flows between the North and South Mediterranean decrease with the spatial dimension where the environmental factors are located. In more detail, the greatest imbalance affecting South Mediterranean countries refers to local impact emissions ( $P M 10, \mathrm{SO}_{2}$ and water footprint) followed by nitrogen flows, $N O_{x}$ (i.e., glocal impact emissions) that show a strong and positive imbalance to the detriment of the same group of countries. The gap tends to be more balanced when global impact emissions $\left(\mathrm{CO}_{2}\right)$ are considered. This is because all missions are highly connected and $\mathrm{CO}_{2}$ represents the central node of the environmental network because all material processes generate $\mathrm{CO}_{2}$ emissions [35-37]. Therefore, each economy affects, and is affected, by these highly interconnected processes. This centrality also explains why $\mathrm{CO}_{2}$ plays a crucial role in global warming. Table 4 provides evidence about the emissions trend with regard to three typologies of environmental flows. In the last decade, data show that North Mediterranean countries have always been exporters of pollution. In contrast, South Mediterranean countries have been net importers of emissions and it has been observed for all environmental flows. Again, we found the greatest imbalance in local impact emissions whose trend has substantially been stable over the observation period.

We observe the same pattern with regards to the nitrogen emissions (glocal): differences between outgoing and incoming flows have substantially remained unchanged during the last two decades. South Med countries have steadily been importers of environmental flows, whereas Northern countries have always been net exporters. However, the gap is slightly lower compared to the local emissions. 
In contrast, data provide evidence of a steady increase of $\mathrm{CO}_{2}$ imported emissions by Southern countries. It is worth noting that, whereas local and glocal emissions show a reversal trend in 2015, data on $\mathrm{CO}_{2}$ suggest that North Mediterranean area have hardly increased their exports; specularly, Southern countries continue to be net importers.

Table 4. Imbalance of Environmental Flows between the North and South Mediterranean areas over the period 2002-2015. Source: Author's elaboration on the Eora MRIO database.

\begin{tabular}{|c|c|c|c|c|c|c|c|c|c|c|c|c|c|c|c|}
\hline & & 2002 & 2003 & 2004 & 2005 & 2006 & 2007 & 2008 & 2009 & 2010 & 2011 & 2012 & 2013 & 2014 & 2015 \\
\hline Global Impact Emissions & $\begin{array}{l}\text { North Med } \\
\text { South Med }\end{array}$ & $\begin{array}{c}0.173 \\
-0.173\end{array}$ & $\begin{array}{c}0.232 \\
-0.232\end{array}$ & $\begin{array}{c}0.266 \\
-0.266\end{array}$ & $\begin{array}{c}0.254 \\
-0.254\end{array}$ & $\begin{array}{c}0.292 \\
-0.292\end{array}$ & $\begin{array}{c}0.303 \\
-0.303\end{array}$ & $\begin{array}{c}0.317 \\
-0.317\end{array}$ & $\begin{array}{c}0.331 \\
-0.331\end{array}$ & $\begin{array}{c}0.375 \\
-0.375\end{array}$ & $\begin{array}{c}0.379 \\
-0.379\end{array}$ & $\begin{array}{c}0.402 \\
-0.402\end{array}$ & $\begin{array}{c}0.409 \\
-0.409\end{array}$ & $\begin{array}{c}0.418 \\
-0.418\end{array}$ & $\begin{array}{c}0.952 \\
-0.952\end{array}$ \\
\hline Glocal Impact Emissions & & & & & & & $\begin{array}{c}0.855 \\
-0.855\end{array}$ & & & & & & & $\begin{array}{c}0.795 \\
-0.795\end{array}$ & $\begin{array}{c}-0.566 \\
0.566\end{array}$ \\
\hline Local Impact Emissions & & $\begin{array}{c}0.933 \\
-0.933\end{array}$ & $\begin{array}{c}0.939 \\
-0.939\end{array}$ & $\begin{array}{c}0.945 \\
-0.945\end{array}$ & $\begin{array}{c}0.949 \\
-0.949\end{array}$ & $\begin{array}{c}0.949 \\
-0.949\end{array}$ & $\begin{array}{c}0.954 \\
-0.954\end{array}$ & $\begin{array}{c}0.958 \\
-0.958\end{array}$ & $\begin{array}{c}0.955 \\
-0.955\end{array}$ & $\begin{array}{c}0.959 \\
-0.959\end{array}$ & $\begin{array}{c}0.955 \\
-0.955\end{array}$ & $\begin{array}{c}0.959 \\
-0.959\end{array}$ & $\begin{array}{c}0.958 \\
-0.958\end{array}$ & $\begin{array}{c}0.958 \\
-0.958\end{array}$ & $\begin{array}{l}-0.645 \\
0.645\end{array}$ \\
\hline
\end{tabular}

We run the same analysis for portfolio investment between the two Mediterranean macroarea. Table 5 shows an unclear pattern of the financial flows direction. On average, North Med countries have been net exporters of equity and, more significantly, in long-term debt, whereas South Med countries have been net buyers of short term debt. The trend analysis highlights how assets of portfolio investments are characterized by different dynamic across the period. The attitude to act as importers or as exporters, although not particularly high, shows a certain variability for equity investment, whereas the graphic on long-term debt reveals that Northern and Southern Mediterranean countries are steadily net buyers and net sellers, respectively. It is worth highlighting that short-term debt, after an initial phase where both groups of countries behave both as importers and exporters, starting from 2010 shows a stable pattern with Northern as importers and Southern as exporters.

Table 5. Imbalance of Financial Flows between the North and South Mediterranean areas over the period 2002-2015. Source: Author's elaboration on Coordinated Portfolio Investment Survey (CPIS) database.

\begin{tabular}{|c|c|c|c|c|c|c|c|c|c|c|c|c|c|c|c|}
\hline & & 2002 & 2003 & 2004 & 2005 & 2006 & 2007 & 2008 & 2009 & 2010 & 2011 & 2012 & 2013 & 2014 & 2015 \\
\hline EQUITY & $\begin{array}{l}\text { North Med } \\
\text { South Med }\end{array}$ & $\begin{array}{c}0.821 \\
-0.821\end{array}$ & $\begin{array}{c}0.415 \\
-0.415\end{array}$ & $\begin{array}{c}0.065 \\
-0.065\end{array}$ & $\begin{array}{c}0.616 \\
-0.616\end{array}$ & $\begin{array}{c}-0.372 \\
0.372\end{array}$ & $\begin{array}{c}0.395 \\
-0.395\end{array}$ & $\begin{array}{c}0.570 \\
-0.570\end{array}$ & $\begin{array}{c}-0.413 \\
0.413\end{array}$ & $\begin{array}{c}0.941 \\
-0.941\end{array}$ & $\begin{array}{c}0.569 \\
-0.569\end{array}$ & $\begin{array}{c}0.279 \\
-0.279\end{array}$ & $\begin{array}{c}0.016 \\
-0.016\end{array}$ & $\begin{array}{l}0.987 \\
-0.987\end{array}$ & $\begin{array}{c}-1.000 \\
1.000\end{array}$ \\
\hline LONG T.D. & $\begin{array}{l}\text { North Med } \\
\text { South Med }\end{array}$ & $\begin{array}{c}0.652 \\
-0.652\end{array}$ & $\begin{array}{c}0.840 \\
-0.840\end{array}$ & $\begin{array}{c}0.793 \\
-0.793\end{array}$ & $\begin{array}{c}0.867 \\
-0.867\end{array}$ & $\begin{array}{c}0.706 \\
-0.706\end{array}$ & $\begin{array}{c}0.786 \\
-0.786\end{array}$ & $\begin{array}{c}0.721 \\
-0.721\end{array}$ & $\begin{array}{c}0.567 \\
-0.567\end{array}$ & $\begin{array}{c}0.697 \\
-0.697\end{array}$ & $\begin{array}{c}0.987 \\
-0.987\end{array}$ & $\begin{array}{c}0.857 \\
-0.857\end{array}$ & $\begin{array}{c}0.735 \\
-0.735\end{array}$ & $\begin{array}{c}0.806 \\
-0.806\end{array}$ & $\begin{array}{c}0.126 \\
-0.126\end{array}$ \\
\hline SHORT T.D. & $\begin{array}{l}\text { North Med } \\
\text { South Med }\end{array}$ & $\begin{array}{c}0.434 \\
-0.434\end{array}$ & $\begin{array}{c}0.854 \\
-0.854\end{array}$ & $\begin{array}{c}-1.000 \\
1.000\end{array}$ & $\begin{array}{c}-1.000 \\
1.000\end{array}$ & $\begin{array}{c}0.765 \\
-0.765\end{array}$ & $\begin{array}{c}-0.599 \\
0.599\end{array}$ & $\begin{array}{c}1.000 \\
-1.000\end{array}$ & $\begin{array}{c}0.962 \\
-0.962\end{array}$ & $\begin{array}{c}-0.992 \\
0.992\end{array}$ & $\begin{array}{c}-1.000 \\
1.000\end{array}$ & $\begin{array}{c}-1.000 \\
1.000\end{array}$ & $\begin{array}{c}-1.000 \\
1.000\end{array}$ & $\begin{array}{c}-1.000 \\
1.000\end{array}$ & $\begin{array}{c}-0.900 \\
0.900\end{array}$ \\
\hline
\end{tabular}

Overall, country-by-country analysis, for both financial and environmental flows, shows an uneven picture and the export of environmental emissions, by the more to less industrialized countries, does not seem confirmed. However, when the flows of incoming and outgoing countries are aggregated and the sample is split into North and South Mediterranean areas, data show a strong imbalance in environmental emissions to the detriment of the latter while a coherent pattern for financial flows is observed, where richer countries increase their equities and bond assets (Figure 6).

With regard to the embroilment of financial and environmental flows across the Mediterrean area, from the present analysis, no clear information emerges on the prominent role of equities in trading with environmental loads embodied in goods. These results contrasts with a previous study focusing on OECD countries [14]. In one case, however, equity shows a significant, positive nexus with $\mathrm{SO}_{2}$. This is the strongest positive nexus observed, and it is more pronounced for opposite flows, suggesting that equity is exported to import coal-intensive products. The strongest negative nexus is exhibited by multiplex flows linking the long-term debt and water. As a matter of fact, water shows the strongest negative, reverse nexus with all financial layers, meaning that the more the network's country tends to trade finance, the less trade embodied water and vice versa. Water is not exchanged for finance as coal intensive goods. It is also worth noting how environmental layers are mostly uncorrelated. Even $\mathrm{CO}_{2}$ shows no significant correlation with energy, a result that contradicts previous studies 
on the global multiple virtual material flows network [15]. On a global scale $\mathrm{CO}_{2}$ and energy show the strongest nexus, foremost for flows in the opposite direction, with an increasing trend beginning with the 2000s. This nexus suggests that, in the world, from the beginning of the century, more and more countries began outsourcing carbon intensive energy and that this was not the case among Mediterranean countries.

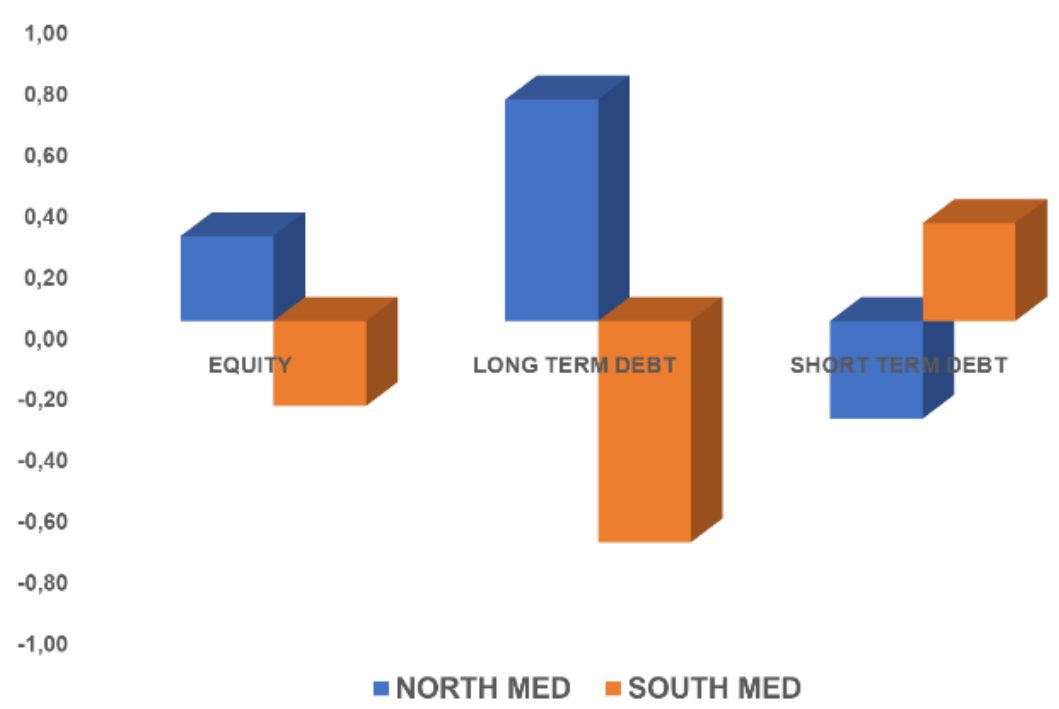

Figure 6. Imbalance of Financial Flows between North and South Mediterranean Areas (average 2002-2015). Source: Authors' elaboration on Coordinated Portfolio Investment Survey (CPIS) database

\section{Conclusions}

The aim of this study was to identify whether financial and environmental flows have been redistributed within the main Mediterranean countries, with particular reference to pollution. Applying advanced methods of correlation and network analysis, we verify the dynamics of transfer processes for environmental flows, classified by pollution features.

Countries we have analysed show heterogeneous behaviour, both with regard to environmental and financial imbalances. However, when we focus on two macro-areas, the results confirm the hypothesis that the most financialised countries (which in our sample coincide with the countries of the north of the Mediterranean and which are part of the European Union) have carried out a process of transfer of financial, energy and environmental flows which constitutes the core of our work.

In particular, the countries of the Northern Mediterranean, typically characterized by a higher GDP, transfer financial and energy resources to the countries of the Southern Mediterranean. Capital and energy allow for increase fixed investments that produce polluting emissions. Our research has made it possible to highlight how the export component of emissions towards the south of the Mediterranean is concentrated in emissions with the greatest local impact. The result is consistent with the relationship between the surplus of the trade balance of the most industrialized countries and the method of accounting for consumption for the attribution of pollutant emissions.

This process is accompanied by a substantial increase in the financial activities of the countries of the North of the Mediterranean to the detriment of those of the South of the Mediterranean, which appear to be more indebted. Even if financial activities show a very weak, often negative, correlation with the environmental flows embodied and only in limited cases, we discover that the economic and financial development of the Nord Med go together with a growing impact on environmental sustainability measured by the various types of emissions covered by our study. After Boyce [11], our study shows how most industrialized countries of the Mediterranean area are widening the economic and financial gap with the countries of the Southern Mediterranean. 
Author Contributions: G.G. wrote the introduction. P.V. has written Sections 2.1, 3.1, 4. F.R. has written Sections $2.2,2.3,2.4,2.5,3.2$. All authors contributed to the final considerations.

Acknowledgments: The authors thank Emanuela Benincasa and Arsenio Stabile for helpful comments and discussions. All remaining errors and omissions are our own.

Conflicts of Interest: The authors declare no conflict of interest.

\section{Abbreviations}

The following abbreviations are used in this manuscript:

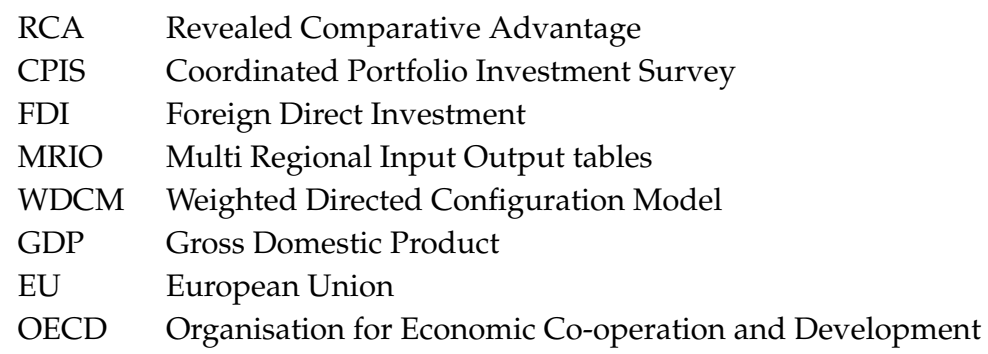

\section{References}

1. Daniele, V.; Malanima, P. Le economie del Mediterraneo tra convergenza e divergenza 1950-2011. In Rapporto Sulle Economie del Mediterraneo 2013; Malanima, P., Ed.; il Mulino: Bologna, Italy, 2013; pp. 13-32.

2. Daniele, V.; Malanima, P. Trends in Mediterranean inequalities 1950-2015. Panoeconomicus 2018. [CrossRef]

3. IPCC Intergovernmental Panel on Climate Change. Climate Change 2014 Report; World Meteorological Organization (WMO): Geneva, Switzerland, 2015.

4. Benchekroun, H.; Chaudhuri, A. Transboundary Pollution and Clean Technologies. Resour. Energy Econ. 2014, 37, 601-619. [CrossRef]

5. Dockner, J.; Long, N. International Pollution Control: Cooperative versus Noncooperative Strategies. J. Environ. Econ. Manag. 1993, 25, 13-29. [CrossRef]

6. Jorgensen, S.; Martin-Herran, G.; Zaccour, G. Dynamic Games in the Economics and Management of Pollution. Environ. Model. Assess. 2010, 15, 433-467. [CrossRef]

7. Martin, W.; Patrick, R.; Tolwinski, B. A Dynamic Game of a Transboundary Pollutant with Asymmetric Players. J. Environ. Econ. Manag. 1993, 25, 1-12. [CrossRef]

8. Copeland, B.; Scott Taylor, S. Trade and Transboundary Pollution. Am. Econ. Rev. 1995, 85, 716-737.

9. Parks, C.; Roberts, T. Inequality and the Global Climate Regime: Breaking the North-South Impasse. Camb. Rev. Int. Aff. 2008, 21, 621-648. [CrossRef]

10. Roberts, T. Global Inequality and Climate Change. Soc. Nat. Resour. 2001, 14, 501-509. [CrossRef]

11. Boyce, J. Inequality As a Cause of Environmental Degradation. Ecol. Econ. 1994, 11, 169-178. [CrossRef]

12. Andrews-Speed, P.; Bleischwitz, R.; Boersma, T.; Johnson, C.; Kemp, G.; VanDeveer, S.D. The Global Resource Nexus. The Struggles for Land, Energy, Food, Water, and Minerals; Transatlantic Academy: Washington, DC, USA, 2012.

13. Font Vivanco, D.; Wang, R.; Hertwich, E. Nexus strength: A novel metric for assessing the global resource nexus. J. Ind. Ecol. 2018, 22, 1473-1486. [CrossRef]

14. Ruzzenenti, F.; Joseph, A.; Ticci, E.; Vozzella, P.; Gabbi, G. Interactions between financial and environmental networks in OECD countries. PLoS ONE 2015, 10, e0136767. [CrossRef] [PubMed]

15. Xu, Z.; Chau, S.N.; Ruzzenenti, F.; Connor, T.; Li, Y.; Tang, Y.; Li, D.; Gong, M.; Liu, J. Evolution of multiple global virtual material flows. Sci. Total Environ. 2019, 568, 659-668. [CrossRef] [PubMed]

16. Gemmetto, V.; Squartini, T.; Picciolo, F.; Ruzzenenti, F.; Garlaschelli, D. Multiplexity and multireciprocity in directed multiplexes. Phys. Rev. E 2016, 4, 042316. [CrossRef] [PubMed]

17. Humanicki, M.; Kelm, R.; Olszewski, K. Foreign Direct Investment and Foreign Portfolio Investment in the contemporary globalized world: Should they be still treated separately? In Narodowy Bank Polski (NBP); Working Paper No. 167. Available online: https://www.nbp.pl/publikacje/materialy_i_studia/167_en.pdf (accessed on 17 June 2019). 
18. Joseph, A.; Guanrong, C. Composite centrality: A natural scale for complex evolving networks. Phys. D 2014, 267, 58-67. [CrossRef]

19. Lane, P.R.; Milesi-Ferretti, G.M. International investment patterns. Rev. Econ. Stat. 2008, 90, 538-549. [CrossRef]

20. Galstyan, V.; Lane, P.R. Bilateral portfolio dynamics during the global financial crisis. Eur. Econ. Rev. 2013, 57, 63-74. [CrossRef]

21. Barigozzi, M.; Fagiolo, G.; Garlaschelli, D. Multinetwork of international trade: A commodity-specific analysis. Phys. Rev. E 2010, 4, 046104. [CrossRef]

22. Squartini, T.; Picciolo, F.; Ruzzenenti, F.; Garlaschelli, D. Reciprocity of weighted networks. Sci. Rep. 2013, 3, 2729. [CrossRef]

23. Garlaschelli, D.; Loffredo, M.I. Maximum likelihood: Extracting unbiased information from complex networks. Phys. Rev. E 2008, 78, 015101(R). [CrossRef]

24. Caro, D.; Pulselli, F.M.; Borghesi, S.; Bastianoni, S. Mapping the international flows of GHG emissions within a more feasible consumption-based framework. J. Clean. Prod. 2017, 147, 142-151. [CrossRef]

25. Caro, D.; Rugani, B.; Pulselli, F.M.; Benetto, E. Implications of the consumerbased perspective for the estimation of GHG emissions: the illustrative case of Luxembourg. Sci. Total Environ. 2015, 508, 67-75. [CrossRef] [PubMed]

26. Ghertner, D.A.; Fripp, M. Trading away damage: Quantifying environmental leakage through consumption-based, life-cycle analysis. Ecol. Econ. 2007, 63, 563-577. [CrossRef]

27. Bastianoni, S.; Pulselli, F.M.; Tiezzi, E. The problem of assigning responsibility for greenhouse gas emissions. Ecol. Econ. 2004, 49, 253-257. [CrossRef]

28. Marques, A.; Rodrigues, J.; Lenzen, M.; Domingos, T. Income-based environmental responsibility. Ecol. Econ. 2012, 84, 57-65. [CrossRef]

29. Balassa, B. Trade liberalisation and 'revealed' comparative advantage 1. Manch. Sch. 1965, 33, 99-123. [CrossRef]

30. Gupta, J.; Van der Leeuw, K.; De Moel, H. Climate change: A 'glocal' problem requiring 'glocal' action. Environ. Sci. 2007, 4, 139-148. [CrossRef]

31. Lambin, E.F.; Meyfroidt, P. Global land use change, economic globalization, and the looming land scarcity. Proc. Natl. Acad. Sci. USA 2011, 108, 3465-3472. [CrossRef]

32. Liu, J.; Mooney, H.; Hull, V.; Davis, S.J.; Gaskell, J.; Hertel, T.; Lubchenco, J.; Seto, K.C.; Gleick, P.; Kremen, C.; et al. Systems integration for global sustainability. Science 2015, 347, 1258832. [CrossRef]

33. Wiedmann, T.; Lenzen, M. Environmental and social footprints of international trade. Nat. Geosci. 2018, 11, 314-321. [CrossRef]

34. Forbes, K.J.; Warnock, F.E. Capital flow waves: Surges, stops, flight, and retrenchment. J. Int. Econ. 2012, 88, 235-251. [CrossRef]

35. Conway, D.; Van Garderen, E.A.; Deryng, D.; Dorling, S.; Krueger, T.; Landman, W.; Lankford, B.; Lebek, K.; Osborn, T.; Ringler, C. Climate and southern Africa's water-energy-food nexus. Nat. Clim. Chang. 2015, 5, 837. [CrossRef]

36. Maris, S.; Teira-Esmatges, M.; Arbonés, A.; Rufat, J. Effect of irrigation, nitrogen application, and a nitrification inhibitor on nitrous oxide, carbon dioxide and methane emissions from an olive (Olea europaea L.) orchard. Sci. Total Environ. 2015, 538, 966-978. [CrossRef] [PubMed]

37. Rulli, M.C.; Bellomi, D.; Cazzoli, A.; De Carolis, G.; D'Odorico, P. The water-land-food nexus of first-generation biofuels. Sci. Rep. 2016, 6, 22521. [CrossRef] [PubMed]

(c) 2019 by the authors. Licensee MDPI, Basel, Switzerland. This article is an open access article distributed under the terms and conditions of the Creative Commons Attribution (CC BY) license (http://creativecommons.org/licenses/by/4.0/). 